\title{
Research Introduction
}

\section{Introduction of Remote Sensing and Geoinformatics researches at Tanta University (Egypt)}

\author{
Alaa Ahmed Masoud \\ Remote Sensing Laboratory, Geology Department, Faculty of Science, Tanta University, Egypt
}

\section{Introduction}

Tanta University is an Egyptian university located in the city of Tanta, Gharbiyah governorate, Egypt (see the following photos). The university is under the direct scientific supervision of the Ministry of Higher Education and under the presidency of Prof. Magdi A. Sabaa, the current president of the university. It was founded first in 1962 as a branch from the University of Alexandria with the faculty of Medicine only and then it became an independent university named University of the Middle Delta in 1972. It had at that time Medicine, Science, Agriculture and Education faculties. Then, its name was changed to Tanta University in 1973.

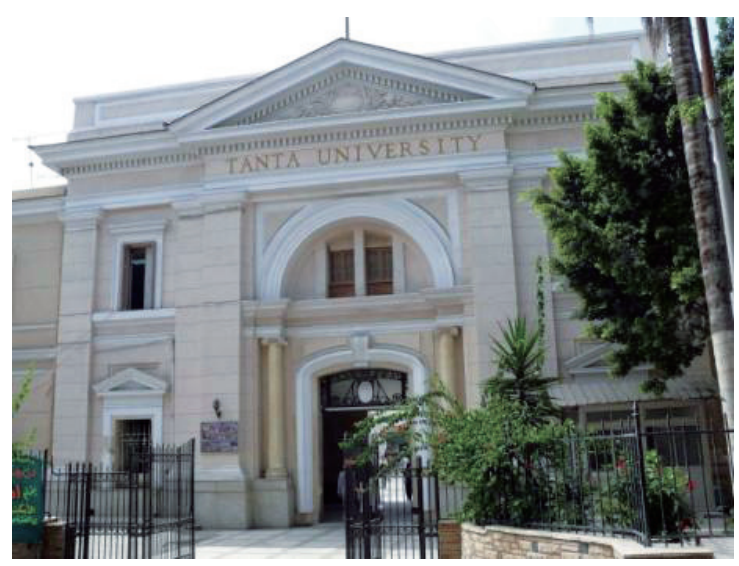

The administrative campus of Tanta University.

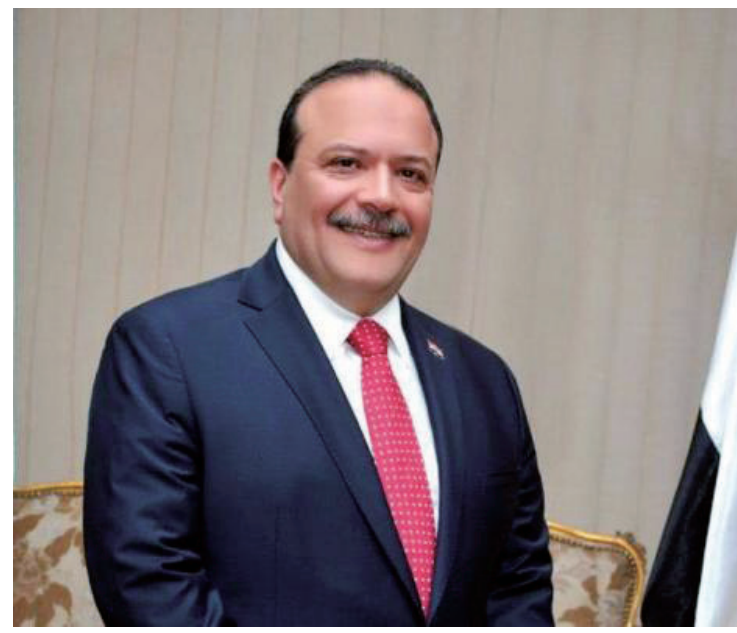

Professor Magdi A. Sabaa President of Tanta University.
The number of faculties is currently 13 colleges and technical institutes - human sciences, science, education, commerce, pharmacy, dentistry, arts, law, nursing, engineering, agriculture, physical education, and the Technical Institute for Nursing.

Tanta University is keen to build an effective academic environment through the continuous development of academic programs for many disciplines in light of the requirements of development plans and to meet the needs of students knowledge and skills in the context of community values and traditions as well as provide educational opportunities and professional development of graduates in various sectors to keep up with progress and achieve the aspirations of the labor market. The University also undertakes to provide the elements of innovation in various fields of scientific research, serious methodology for the development of science and knowledge, sustainable development and solving social problems.

TU enrolls about 130,000 students in 221 bachelor' s programs, and 1544 master/doctor degrees in first-class disciplines (see http://tdb2.tanta.edu.eg/acad_catalog/)

\section{Space science application research}

Remote Sensing, GIS, and Geoinformatics at TU are carried out in several faculties, covering many fields such as Science, Engineering, Agriculture and Arts. This article focuses only on the main researches at the Faculty of Science, lab of remote sensing.

Remote Sensing Lab. (RSL) was established in 2004, after the return of Prof. Alaa A. Masoud from his PhD awarded from the Faculty of Science, Department of Geosciences at Osaka City University, Japan in 2003. RSL carries out a multitude of research work devoted mainly to strictly realize the sustainable development of Egypt's vision 2030. Research focuses on environmental applications of the space technology to solve pressing problems such as soil salinization, groundwater pollution, renewable energy assessment, natural resources evaluation and natural hazard assessment appraising the use of large-scale remote sensing imageries.

RSL at TU cooperated with many local and world institutions and universities from Japan, Vietnam, Saudi Arabia, South Korea, Indonesia, and China.

Examples of the lab researches are the soil salinity mapping 
(Fig. 1) at Burg Al-Arab, North Coast of Egypt (Masoud, 2014), pesticide pollution of the groundwater (Fig. 2), eastern districts of Gharbiya govenorate (Masoud et al., 2018).

In addition, detection of lineaments (Fig. 3) and structural features from digital data was a prime objective of RSL with LINDA (LINeament Detection and Analysis) software (Fig. 4)
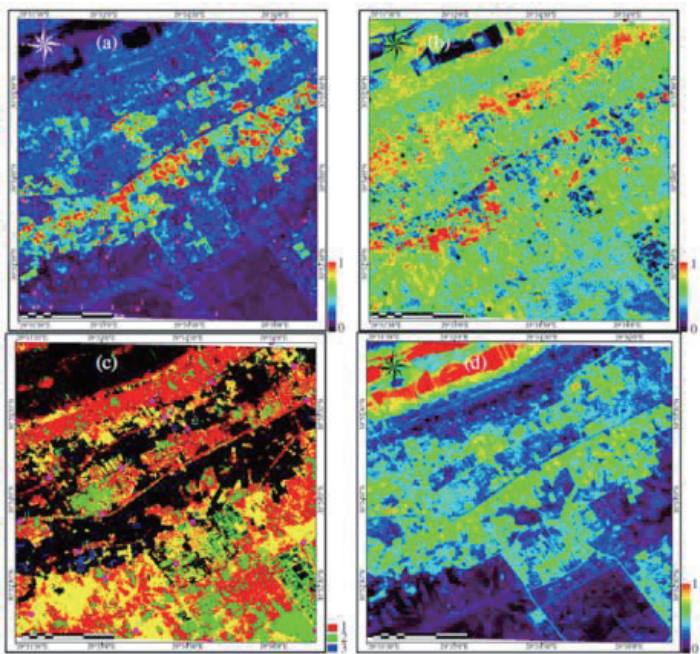

Figure 1.Maps of the soil salinity: (a) LSU abundances, (b) MTMF scores, (c) SAM classes, and (d) Wetness Index values. The unclassified field is shown in black color on SAM (Masoud, 2014).

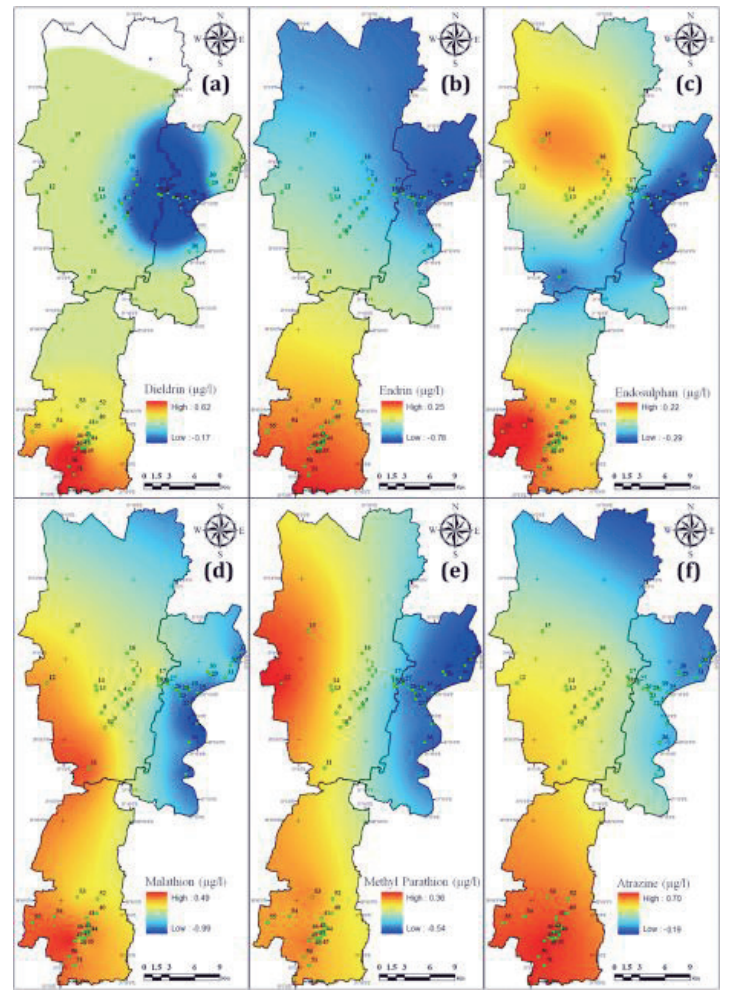

Figure 2.Maps showing spatial time-step trend magnitude of (a) dieldrin, (b) endrin, (c) endosulphane sulfate, (d) malathion, (e) methyl parathion, (f) atrazine, and (g) simazine, along with maps of (h)the silty clay layer thickness and (i) the groundwater level (Masoud et al., 2018).

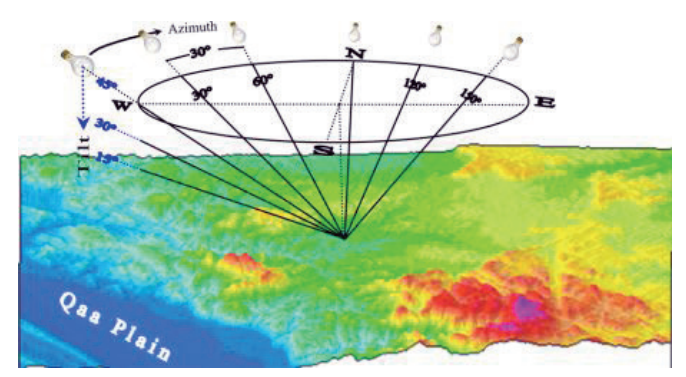

Figure 3.Schematic idea of the adaptive-tilt multi-directional shading (ATMDS) technique with six illumination azimuths at 30_interval from the northward and tilt angle for LINDA (Masoud and Koike, 2011).

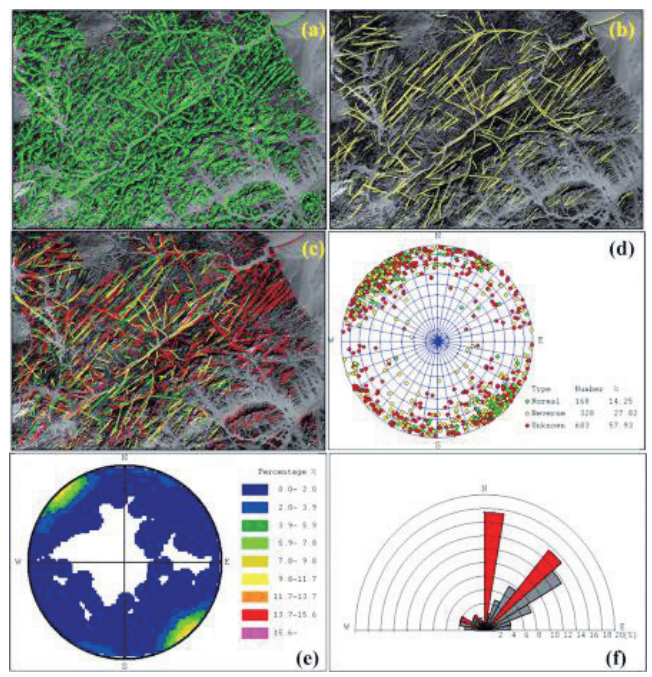

Figure 4.Flow of LINDA using DEM data: (a) Segments overlaid on shades blended with colored DEM; (b) Bézier-smoothed lineaments; (c) BSP-smoothed lineaments with fault types (yellow: normal, green: reverse, and red: strike-slip); (d) distribution of poles of interpreted fracture- or fault-related planes with fault types; (e) pole density using Schmidt nets (lower hemisphere projection); (f) rose diagram for strikes of lineaments (Masoud and Koike, 2017).

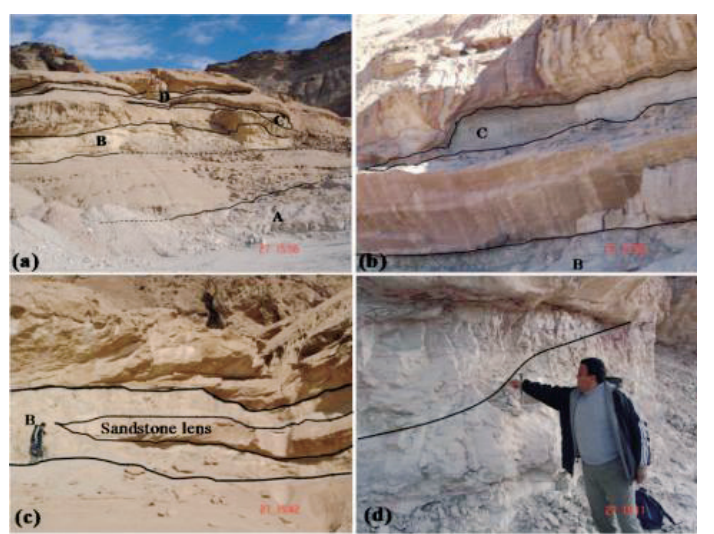

Figure 5.Field photographs showing (a) kaolin layers (A to D) alternating with sandstone; (b) sandy kaolin layers (B and C); (c) sandstone lens within layer B; and (d) channel surface within kaolin (Masoud et al., 2013). 
as the first automated techniques superior to many techniques in the field was published (Masoud and Koike, 2011; Masoud and Koike, 2017).

Assessment of mineral resources is among the objectives of RSL, e.g., kaolinite (Fig. 5) of Sinai, Egypt (Masoud et al., 2013).

Geoinformatics played also a key role in assessing the flash flood potential and groundwater artificial recharging in Sinai, Egypt (e.g., Fig. 6; Masoud, 2011).

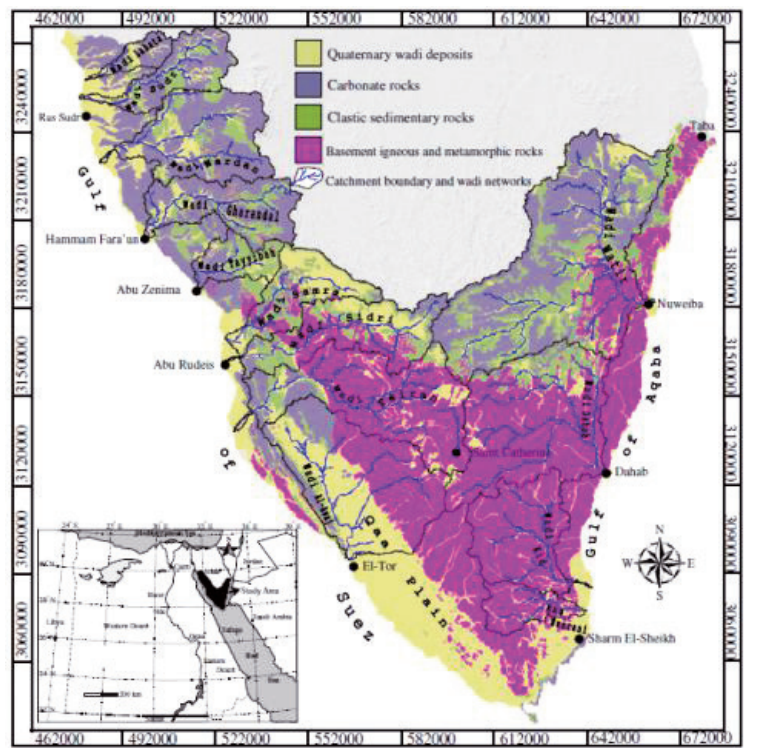

Figure 6. Location and physiographic features of southern Sinai (Masoud and Koike, 2011).

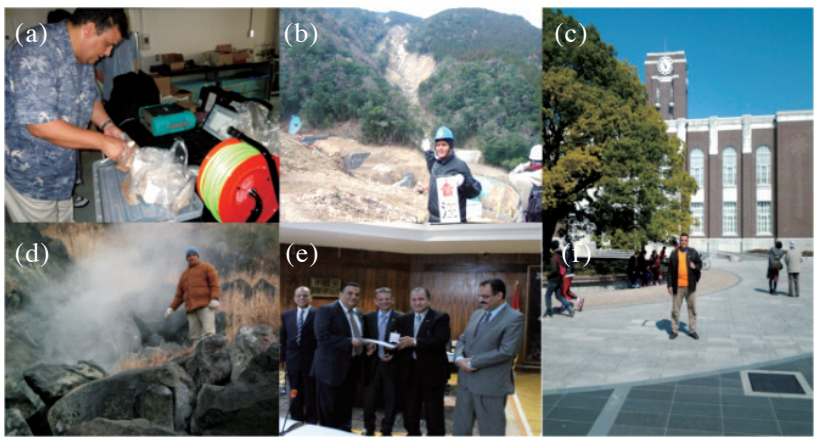

Figure 7. Prof. Masoud lab activities and field visits: a) spectrometry measurements at Prof. Koike's lab in Kyoto University, b) Landslide risk assessment, c) geothermal potential field investigations in the Hohi area, central Kyushu, Japan, d) receiving Tanta University incentive award in 2013, and e) vist at Kyoto University in 2016.
Geoinformation technologies have been also applied for soil salinization, mineral, and geothermal resources, landslide assessment (Fig. 7) with lab works conducted in Kumamoto University and Kyoto University (Japan). The research of the lab has helped Prof. Masoud to get many national awards such as the Tanta University Incentive award in 2013, state Incentive award 2014, and the medal of Excellence from the President Abdel Fattah El-Sisi in 2017.

\section{Future Projects}

RSL future projects will focus on assessing the renewable energy potential integrating hyperspectral remote sensing and in-situ measurements in a GIS environment in North Nile Delta, Egypt.

\section{References}

Masoud, A. A. (2011) Runoff modeling of the Wadi systems for estimating flash flood and groundwater recharge potential in southern Sinai, Egypt. Arabian Journal of Geosciences, vol. 4 , nos. 5-6, pp. 785-801. https://doi.org/10.1007/s12517-0090090-9

Masoud, A. A. (2014) Predicting Salt Abundance in Slightly Saline Soils from Landsat ETM+ Imagery Using Spectral Mixture Analysis and Soil Spectrometry. Geoderma, vols. 217-218,pp. 45-56. https://doi.org/10.1016/ j.geoderma.2013.10.027

Masoud, A. A., Abdel-Wahab Arafa, N. A. And El-Bouraie, M. (2018) Patterns and Trends of the Pesticide Pollution of the Shallow Nile Delta Aquifer (Egypt). Water Air and Soil Pollution, vol. 229, no. 5: 148.https://doi.org/10.1007/ s11270-018-3802-5.

Masoud, A. A. and Koike, K. (2011) Morphotectonics inferred from the analysis of topographic lineaments auto-detected from DEMs: Application and validation for the Sinai Peninsula, Egypt. Tectonophysics, vol. 510, nos. 3-4, pp. 291308. https://doi.org/10.1016/j.tecto.2011.07.010

Masoud, A. A. and Koike, K. (2017) Applicability of computeraided comprehensive tool (LINDA: LINeament Detection and Analysis) and shaded digital elevation model for characterizing and interpreting morphotectonic features from lineaments. Computers \& Geosciences, vol. 106, pp. 89-100. https://doi.org/10.1016/j.cageo.2017.06.006

Masoud, A. A., Christidis, G. and Koike, K. (2013) Characterization of El-Tihkaolin quality using mineralogical, geochemical, and geostatistical analyses. Clay Minerals, vol. 48, no. 1, pp. 1-15. https://doi.org/10.1180/ claymin.2013.048.1.01. 